\title{
Effect of storage conditions on mechanical properties of resin composite blanks for CAD/CAM crowns
}

\author{
Yasushi HIBINO, Yuko NAGASAWA, Yoshikazu EDA, Hirotaka SHIGETA and Hiroshi NAKAJIMA \\ Division of Dental Biomaterials Science, Department of Restorative and Biomaterials Sciences, Meikai University School of Dentistry, 1-1 Keyakidai, \\ Sakado, Saitama 350-0283, Japan \\ Corresponding author, Yasushi HIBINO; E-mail: hibino@dent.meikai.ac.jp
}

\begin{abstract}
The objective of this study was to examine the effects of storage conditions on the flexural strengths of resin composite materials for CAD/CAM restorations. Seven commercially available resin composite CAD/CAM blanks were examined. Rectangular specimens $(4.0 \times 1.2 \times 4.0 \mathrm{~mm})$ of each material were trimmed from the blanks and subjected to thermal cycling between $5^{\circ} \mathrm{C}$ and $55^{\circ} \mathrm{C}$ in deionized water at 10,000 cycles or stored in $37^{\circ} \mathrm{C}$ deionized water for one week or air for one day ( $n=10$ for each condition). The difference in storage condition between water immersion and thermal cycling did not affect the flexural strengths of resin composite materials for $\mathrm{CAD} / \mathrm{CAM}$ examined in this study. The resin composite block CS300 made from Bis-MEPP and UDMA showed the greatest flexural strength under all storage conditions and less deterioration of strength by thermal cycling and water immersion among the resin composite blocks tested.
\end{abstract}

Keywords: Resin composite block for CAD/CAM crowns, Flexural strength, Storage conditions, Thermal cycling, Elastic modulus

\section{INTRODUCTION}

In recent years, crown restorations are apt to be metalfree due to increased concerns about the incidence of metal allergy with metallic restorations and increased consciousness of esthetic appearance among patients. In addition, with the rapid development of digital technologies, the application of $\mathrm{CAD} /$ CAM in fabricating dental restorations has become widespread $^{1,2}$. Metallic materials, ceramic materials and resin composites are used for crown restorations. Since the use of resin composite materials for CAD/ CAM as posterior restoration materials was approved under the Japanese social health insurance system in 2014, many manufacturers are trying to develop new resin composite materials for CAD/CAM. This is not only for the Japanese domestic market; the use of resin composite materials for CAD/CAM will spread to other countries if these materials offer acceptable properties for posterior crown restorations.

Resin composites for CAD/CAM are made into block shapes by a polymerization process, placing a polymer matrix resin containing fillers under high pressure and high temperature conditions ${ }^{3)}$. As resin composite blocks (or blanks) for CAD/CAM can possess a higher degree of polymerization and greater content of filler, these materials show greater and more stable strengths in comparison to direct restorative resin composites. Previous studies on resin composite blanks have examined mechanical properties such as wear behavior, hardness, flexural strength, flexural modulus, glossiness after polishing, and adhesive strength to tooth structures using resin cements ${ }^{4-15}$. Hamakubo et al. ${ }^{4)}$ reported that $\mathrm{CAD} / \mathrm{CAM}$ resin blocks exhibited lower compressive strength but comparable flexural strength in comparison with prosthodontic resins or crown and bridge. Lauvahutanon et al. ${ }^{5,6)}$ found that after 10,000 thermocycles the flexural strength of CAD/ CAM resins was reduced but their amount of wear was lower than conventional posterior resin composites. Kamonkhantikul et $a l .{ }^{10)}$ reported that although some $\mathrm{CAD} / \mathrm{CAM}$ resin blocks showed increased surface roughness after a toothbrush wear test with increased brushing cycles, the majority of CAD/CAM blocks showed significantly reduced values of both surface roughness and degree of gloss after brushing.

As for the adhesion of resin cements to CAD/CAM resin blocks, silane treatment after sandblasting of $\mathrm{CAD} /$ CAM resin surfaces showed greater adhesive strength than silane or sandblasting treatment with no surface treatment ${ }^{12)}$. Cleaning using an ultrasonic cleaner or phosphoric acid was reported not to affect the adhesive strength of resin cements ${ }^{13)}$. Cekic-Nagas et al. ${ }^{14)}$ found that surface treatment using 9.6\% hydrofluoric acid solution did not increase the adhesive strength between $\mathrm{CAD} / \mathrm{CAM}$ resin blocks and resin cements.

Materials for crown restorations require high mechanical strength and durability. In the oral cavity, deterioration of resin composite restorative materials is caused by hydrolysis of the silane bonds between the matrix resin and filler during extended periods of water contact, resulting in separation of the filler particles from the matrix ${ }^{16-19)}$. In addition, water sorption into composite materials was reported to reduce their mechanical properties ${ }^{20,21}$. This deterioration behavior found in resin composite filling materials would likely also occur in resin composite restorations made by $\mathrm{CAD} / \mathrm{CAM}$. Therefore, investigation of the deterioration behavior, particularly as it affects the mechanical properties, of these materials in water will be useful in understanding the longevity of materials in the oral cavity and in improving and developing new materials. 
The objective of this study was to examine the mechanical properties of resin composite materials for $\mathrm{CAD} / \mathrm{CAM}$, including a newly-developed resin composite material intended for use in molar restorations. We conducted a thermal cycling experiment to investigate the mechanical durability of the resin composite materials for CAD/CAM blanks.

The hypothesis to be tested in this study was that the flexural strength of CAD/CAM resin blocks is affected by different storage conditions, i.e., whether the specimens are kept in air or water, or subjected to thermal cycling.

\section{MATERIALS AND METHODS}

\section{Materials}

Six commercially-available resin composite CAD/CAM blanks and a newly-developed resin composite CAD/ CAM blank (Cerasmart 300, GC, Tokyo, Japan) were examined (Table 1). Table 1 also shows the composition data from the manufacturers, lot numbers and other information.

\section{Methods}

1. Hardness measurements

The hardness value of each resin composite blank $(12.0 \times 14.0 \times 18.0 \mathrm{~mm})$ was determined using a microVickers hardness tester (HM-102, Mitsutoyo, Kanagawa, Japan) at $0.98 \mathrm{~N}$ of loading for $30 \mathrm{~s}$ at $23 \pm 2^{\circ} \mathrm{C}$ and $50 \pm 10 \%$ relative humidity in air. Five measurement points were randomly selected on the lateral walls of blank surfaces. The measured values were averaged for each blank, and five blanks for each resin composite were examined. The results were analyzed using one-way ANOVA followed by Scheffé's test at $\alpha=0.05$ (SPSS Statistics 20, IBM, Armonk, NY, USA and StatMate V, ATMS, Tokyo, Japan).

\section{Flexural strength measurements}

The flexural strength of $\mathrm{CAD} / \mathrm{CAM}$ resin blocks was determined according to ISO6872:2015 ${ }^{22)}$ and JADMAS 245:201723). Rectangular specimens measuring 4.0 $\pm 0.2 \times$ $1.2 \pm 0.2 \times 14.0 \mathrm{~mm}$ were cut from the resin composite blanks. The surfaces of specimens were finished using No.2000 SiC abrasive paper. Thirty specimens were prepared for each resin composite. Specimens were randomly divided into three groups of ten specimens each.

Of the 30 specimens, ten specimens were kept in air at $23 \pm 2^{\circ} \mathrm{C}$ for one day. Another ten specimens were subjected to thermal cycling between $5^{\circ} \mathrm{C}$ and $55^{\circ} \mathrm{C}$ in deionized water for 10,000 cycles. Cycling was conducted for $60 \mathrm{~s}$ at each temperature with $30 \mathrm{~s}$ of dwell time in air at $23 \pm 2^{\circ} \mathrm{C}$ between different temperature conditions (total of $3 \mathrm{~min}$ per cycle). The remaining ten specimens were immersed in deionized water at $37 \pm 2^{\circ} \mathrm{C}$ for 7 days.

The specimens after thermal cycling or storage in either water or air were subjected to flexural strength measurements. The flexural strengths of specimens were determined using a three-point bending jig (12.0 $\mathrm{mm}$ span length with a $2.0 \mathrm{~mm}$ diameter supporting or loading rod) at $1.0 \mathrm{~mm} / \mathrm{min}$ of crosshead speed in a universal testing machine (Instron 3366, Instron, Boston, USA) in air at $23 \pm 2^{\circ} \mathrm{C}$. The flexural strength of each specimen was calculated from the fracture load of the specimen using the following equation.

Table 1 Resin composite blocks for CAD/CAM crowns used in this study

\begin{tabular}{|c|c|c|c|c|c|}
\hline Product & Manufacturer & Lot No. & Composition & Color & Code \\
\hline \multicolumn{6}{|l|}{ Resin composite } \\
\hline Cerasmart 300 & $\mathrm{GC}$ & 17062310 & $\begin{array}{l}\text { Monomer: Bis-MEPP, UDMA } \\
\text { Filler: } \mathrm{SiO}_{2}, \mathrm{Ba} \text { glass }\end{array}$ & A3-LT & CS300 \\
\hline Cerasmart 270 & $\mathrm{GC}$ & 17062310 & $\begin{array}{l}\text { Monomer: Bis-MEPP, UDMA } \\
\text { Filler: } \mathrm{SiO}_{2}, \mathrm{Ba} \text { glass }\end{array}$ & A3-LT & CS270 \\
\hline Shofu Block HC & Shofu & 0117310 & $\begin{array}{l}\text { Monomer: UDMA, TEGDMA } \\
\text { Filler: } \mathrm{SiO}_{2} \text {, Microfumed } \mathrm{SiO}_{2} \text {, } \\
\text { Zirconium silicate }\end{array}$ & A3-LT & $\mathrm{HC}$ \\
\hline KZR-CAD HR2 & Yamakin & 20021713 & $\begin{array}{l}\text { Monomer: UDMA, TEGDMA } \\
\text { Filler: } \mathrm{SiO}_{2}-\mathrm{Al}_{2} \mathrm{O}_{3}-\mathrm{ZrO}_{2}, \mathrm{SiO}_{2}\end{array}$ & A3 & KZR \\
\hline $\begin{array}{l}\text { Katana Avencia } \\
\text { Block }\end{array}$ & Kuraray-Noritake & 000510 & $\begin{array}{l}\text { Monomer: UDMA } \\
\text { Filler: } \mathrm{SiO}_{2}, \mathrm{Al}_{2} \mathrm{O}_{3}\end{array}$ & A3-LT & AVE \\
\hline Estelite Block & Tokuyama Dental & 044067 & $\begin{array}{l}\text { Monomer: UDMA, TEGDMA } \\
\text { Filler: } \mathrm{SiO}_{2} \text {, Zirconia filler }\end{array}$ & A3-LT & EST \\
\hline \multicolumn{6}{|l|}{ Hybrid ceramic } \\
\hline $\begin{array}{l}\text { Vita Enamic for } \\
\text { Kavo Arctica }\end{array}$ & Kavo Dental & 60870 & $\begin{array}{l}\text { Monomer: UDMA, TEGDMA } \\
\text { Filler: Feldspar ceramic enriched } \\
\text { with } \mathrm{Al}_{2} \mathrm{O}_{3}\end{array}$ & 3M2-T & ENA \\
\hline
\end{tabular}


$\delta=3 P l / 2 w b^{2}$

where $\delta$ is flexural strength $(\mathrm{MPa}), P$ is fracture load $(\mathrm{N}), l$ is the span length between support rods, $w$ is specimen width $(\mathrm{mm})$ and $b$ is specimen thickness (mm).

The results were analyzed using two-way ANOVA followed by Scheffé's test at $\alpha=0.05$.

3. Flexural modulus measurements

The flexural modulus of each specimens was calculated from the load-deflection curve when the flexural strength of the specimen was obtained in the universal testing machine. The results were analyzed using oneway ANOVA followed by Scheffé's test at $\alpha=0.05$.

4. Determination of inorganic filler contents in resin composites

A specimen measuring $2.0 \times 1.2 \times 2.0 \mathrm{~mm}$ was cut from a flexural strength test specimen stored in air after the strength test. After the mass of flexural strength test specimen which was subjected to air storage condition was measured, the specimen was heated in air using TG-DTA (Thermo plus EVO2 TG8120, Rigaku, Tokyo, Japan) at $10^{\circ} \mathrm{C} / \mathrm{min}$ of heating rate up to $900^{\circ} \mathrm{C}$ with a 3 -h holding time and the mass of specimen was recorded. The mass of specimen after heating was divided by that before heating to obtain mass\% of inorganic filler content because the residue of specimen after heating was believed to be the inorganic components. Three specimens for each resin composite material were examined.

The results were analyzed using ANOVA followed by Scheffé's test at $\alpha=0.05$.

5. Scanning electron microscopic observation

The fractured surfaces of specimens after the flexural strength test were examined using a scanning electron microscope (JSM-6360LV, JEOL, Tokyo, Japan). SEM observation was performed on the compressed side (upper side) and tension stressed side (lower side) of the specimens. The specimens were coated with gold film (20 nm thick) and observed at $20 \mathrm{kV}$ of acceleration voltage.

\section{RESULTS}

\section{Hardness}

Vickers hardness numbers of the resin composite blanks examined are listed in Table 2. The results of one-way ANOVA indicated significant differences among the resin composite blanks ( $\mathrm{F}=2963.47, p<0.0001$, Table 3$)$.

The resin composite ENA showed the greatest hardness value among the materials examined $(p<0.05)$. The resin composites CS300 and EST were significantly harder than CS270, HC, KZR and AVE $(p<0.05)$. There were no significant differences in hardness values between CS300 and EST, between HC and AVE, between KZR and AVE, or among CS270, KZR and AVE $(p>0.05)$.

\section{Flexural strength}

Figure 1 shows the flexural strengths of the resin composites. Flexural strength of the resin blocks ranged from 87 to $290 \mathrm{MPa}$. Significant effects of the resin block products $(\mathrm{F}=405.004, p<0.0001)$ and the

Table 2 Vickers hardness numbers of resin composite blocks used in this study

\begin{tabular}{lc}
\hline Product & Vickers hardness number \\
\hline CS300 & $94.2(2.0)^{\mathrm{a}}$ \\
CS270 & $82.7(2.8)^{\mathrm{b}}$ \\
HC & $71.6(2.5)^{\mathrm{c}}$ \\
KZR & $82.1(3.2)^{\mathrm{b}, \mathrm{d}}$ \\
AVE & $76.3(2.9)^{\mathrm{b}, \mathrm{c}, \mathrm{d}}$ \\
EST & $96.4(3.3)^{\mathrm{a}}$ \\
ENA & $254.2(1.5)$ \\
\hline
\end{tabular}

( ): SD

Same lower-case letters indicate no statistical differences $(p>0.05)$ among the resin composite blocks.

Table 3 Summary of analysis of variance for Vickers hardness numbers of resin composite blocks for CAD/CAM crowns

\begin{tabular}{lcrrrr}
\hline \multicolumn{1}{c}{ Source } & Type III Sum of squares & df & Mean Square & F-value & $p$-value \\
\hline Resin composite block & $126,641.342$ & 6 & $21,106.890$ & $2,963.647$ \\
Error & 199.414 & 28 & 7.122 & - \\
Total & 126840.756 & 34 & - & - \\
\hline
\end{tabular}




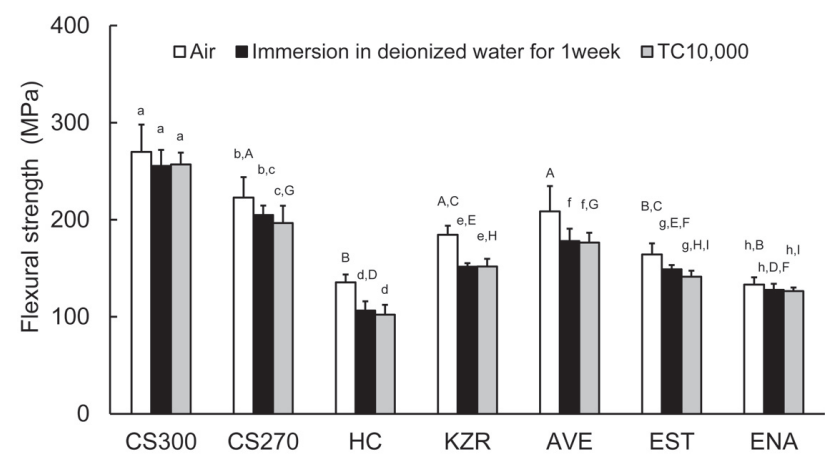

Fig. 1 Flexural strengths of resin composite blocks for $\mathrm{CAD} / \mathrm{CAM}$ crowns after different storage conditions.

Same lower-case letters indicate no significant differences $(p>0.05)$ among the different storage conditions for each resin composite block.

Same upper-case letters indicate no significant differences $(p>0.05)$ among the different resin composite blocks for each storage condition.

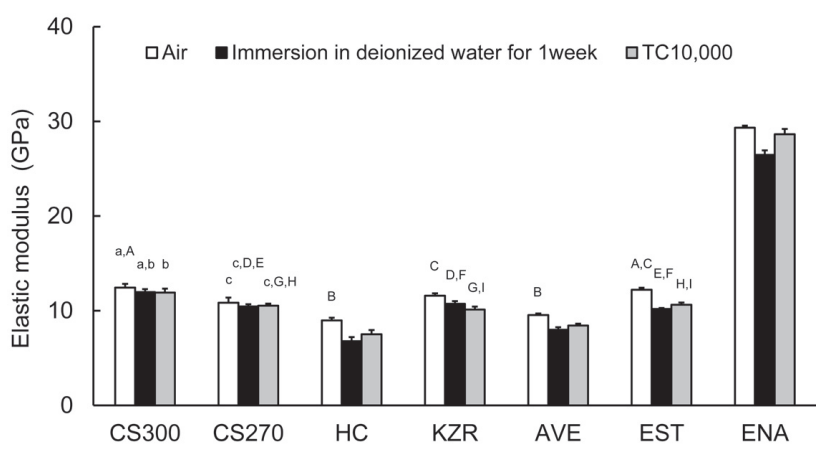

Fig. 2 Elastic moduli of resin composite blocks for CAD/ CAM crown after different storage conditions. Same lower-case letters indicate no significant differences $(p>0.05)$ among the different storage conditions for each resin composite block.

Same upper-case letters indicate no significant differences $(p>0.05)$ among the different resin composite blocks for each storage condition.

Table 4 Summary of analysis of variance for flexural strength of resin composite blocks for CAD/CAM crowns

\begin{tabular}{lrrrrc}
\hline \multicolumn{1}{c}{ Source } & Type III Sum of squares & df & Mean Square & F-value & $p$-value \\
\hline Resin composite block & $455,814.549$ & 6 & $75,969.091$ & 405.004 & 0.000 \\
Storage condition & $19,212.780$ & 2 & $9,606.390$ & 51.213 & 0.000 \\
Resin composite block & $3,744.574$ & 12 & 312.048 & 1.664 & 0.078 \\
Storage condition & $35,451.867$ & 189 & 187.576 & - & - \\
Error & $514,223.770$ & 209 & - & - & - \\
Total & & & & & - \\
\hline
\end{tabular}

storage conditions $(\mathrm{F}=251.213, p<0.0001)$ were found for the flexural strengths, but there was no significant interaction between the resin block products and storage condition ( $\mathrm{F}=1.664, p>0.05)$ (Table 4$)$.

The resin composite blank CS300 had greater flexural strength than the other blanks in all storage conditions $(p<0.05)$. HC showed the least flexural strength among the resin composite blocks in all storage conditions $(p<0.05)$. CS300 and ENA did not vary significantly in flexural strength for all storage conditions $(p>0.05)$. The flexural strengths of other resin blocks, CS270, HC, KZR, AVE and EST, stored in air were significantly greater than those when stored in water for 7 days and thermocycled $(p<0.05)$. No resin blocks showed significant differences in flexural strength between storage in water for 7 days and the thermal cycling $(p>0.05)$. In the storage condition, the flexural strengths of the resin composite blanks stored in air showed significantly greater than those when stored in water for 7 days and thermocycled $(p<0.05)$.

The difference in storage condition between water immersion and thermal cycling did not affect the flexural strengths of resin composite materials for CAD/CAM examined in this study.

Elastic modulus

The elastic modulus values obtained by flexural strength testing are shown in Fig. 2. The values of elastic modulus ranged from 6.4 to $30.1 \mathrm{GPa}$. ANOVA indicated significant effects of the resin block products $(\mathrm{F}=12821.373, p<0.0001)$ and the storage conditions $(\mathrm{F}=419.113, p<0.0001)$ on the elastic modulus values. A significant interaction was also found between the resin block products and the storage conditions ( $\mathrm{F}=23.761$, $p<0.0001$ ) (Table 5). In all storage conditions, ENA had the highest and $\mathrm{HC}$ had the lowest elastic modulus values among the resin blocks $(p<0.05)$. No significant differences in elastic modulus values were found for CS270 among the different storage conditions ( $p>0.05)$. There were no significant differences in the elastic modulus values of CS300 between storage in air and 7 days' immersion in water or between 7 days' immersion and thermal cycling $(p>0.05)$. The elastic modulus values of $\mathrm{HC}, \mathrm{KZR}, \mathrm{AVE}, \mathrm{EST}$ and ENA were significantly affected by the storage conditions $(p<0.05)$. 
Table 5 Summary of analysis of variance for elastic modulus of resin composite blocks for CAD/CAM crowns

\begin{tabular}{|c|c|c|c|c|c|}
\hline Source & Type III Sum of squares & df & Mean Square & F-value & $p$-value \\
\hline Resin composite block & $8,760.313$ & 6 & $1,460.052$ & $12,821.373$ & 0.000 \\
\hline Storage condition & 95.454 & 2 & 47.727 & 419.113 & 0.000 \\
\hline $\begin{array}{l}\text { Resin composite block } \times \\
\text { Storage condition }\end{array}$ & 32.469 & 12 & 2.706 & 23.761 & 0.000 \\
\hline Error & 21.523 & 189 & 0.114 & - & - \\
\hline Total & $8,909.759$ & 209 & - & - & - \\
\hline
\end{tabular}

Table 6 Summary of analysis of variance for content of inorganic filler of resin composite blocks for CAD/CAM crowns

\begin{tabular}{lccccc}
\hline \multicolumn{1}{c}{ Source } & Type III Sum of squares & df & Mean Square & F-value & $p$-value \\
\hline Resin composite block & $1,469.378$ & 6 & 244.896 & $2,508.816$ & -0.000 \\
Error & 1.367 & 14 & 0.098 & - \\
Total & $1,470.745$ & 20 & - & - \\
\hline
\end{tabular}

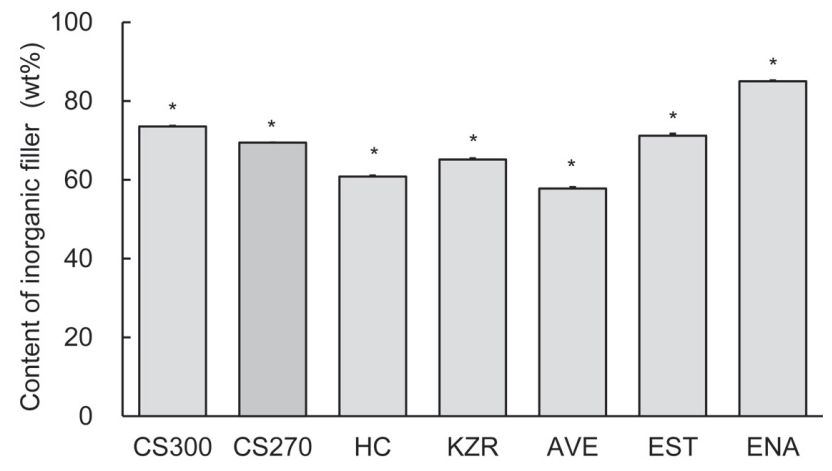

Fig. 3 Inorganic filler contents of resin composite blocks for CAD/CAM crown.

An asterisk symbol $(*)$ indicate significant differences $(p<0.05)$ for each resin composite block.

Inorganic filler contents of resin composite blanks

Inorganic filler contents in the blocks are shown in Fig. 3. The amounts of inorganic filler content ranged from 57.4 to 85.2 mass\%. The results of 1-way ANOVA indicated significant differences among the resin blocks $(\mathrm{F}=2508.816, p<0.0001)$ (Table 6). ENA had the highest filler content and AVE the least, among the resin blocks $(p<0.05)$. There were significant differences in filler content among the resin block products $(p<0.05)$.

Relationships of the inorganic filler content to flexural strength and elastic modulus

Figure 4 shows the relationships between inorganic filler content and flexural strength of all blocks examined. No significant correlation was found between inorganic filler content and flexural strength $(p>0.05)$. The relationships between inorganic filler content and elastic modulus values are shown in Fig. 5. A significant

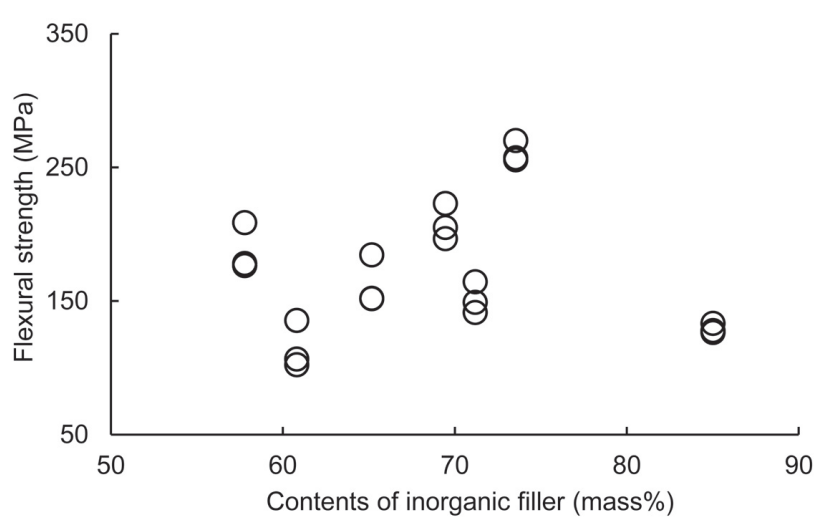

Fig. 4 Relationship between content of inorganic filler and flexural strength of resin composite blocks for CAD/CAM crowns.

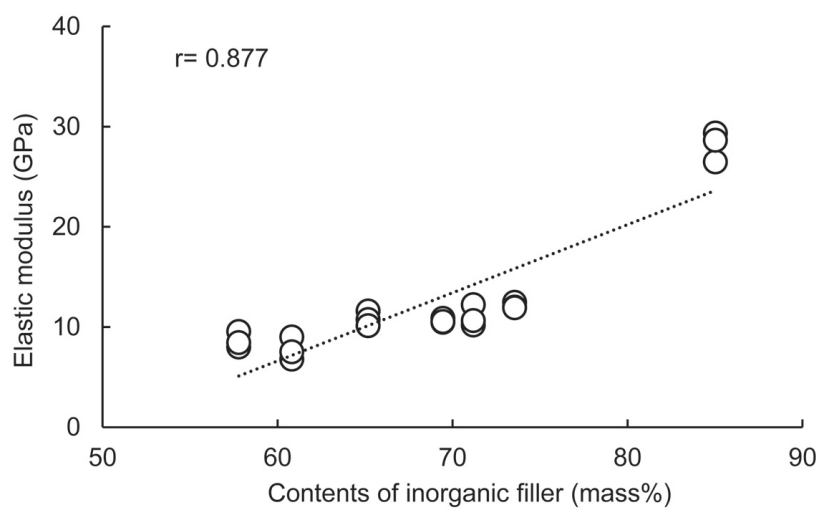

Fig. 5 Relationship between content of inorganic filler and elastic modulus of resin composite blocks for $\mathrm{CAD} / \mathrm{CAM}$ crowns. 
positive correlation was found between filler content and elastic modulus value $(\mathrm{r}=0.877, p<0.05)$.
Observation of facture surfaces of specimens fractured in flexural strength tests

Figures 6 to 9 show representative fractured surfaces of specimens after the flexural strength tests. Figure 6

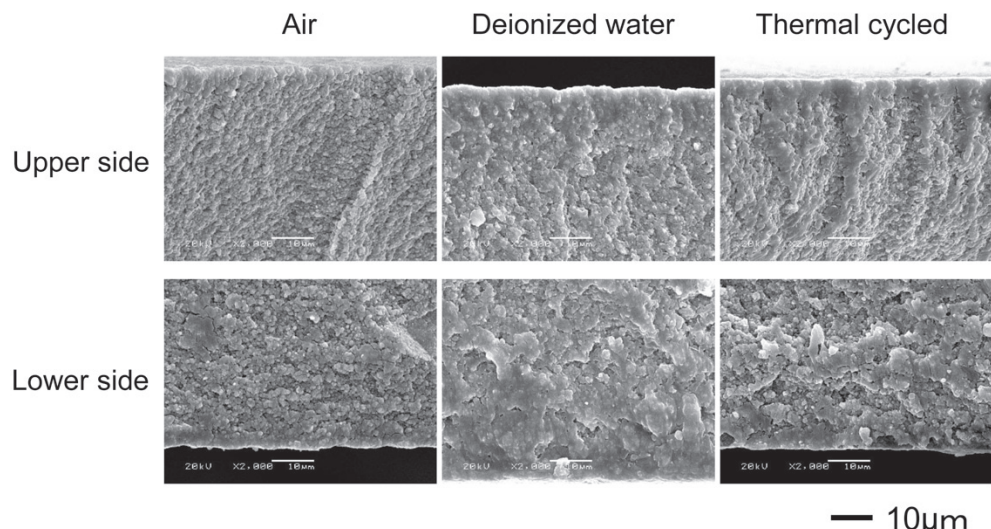

Fig. 6 Fractured surfaces of specimens after flexural strength tests by scanning electron microscope (CS300).

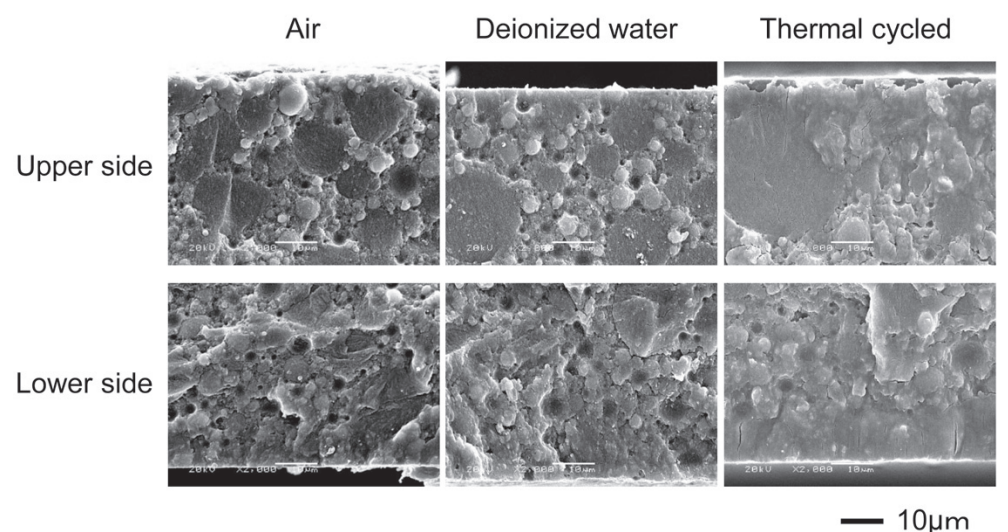

Fig. $7 \quad$ Fractured surfaces of specimens after flexural strength tests by scanning electron microscope (HC).

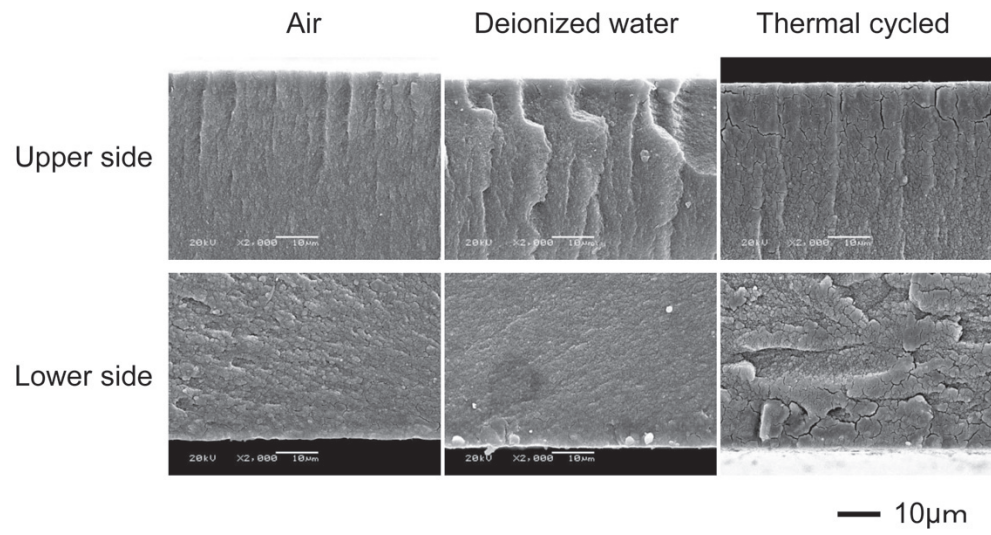

Fig. 8 Fractured surfaces of specimens after flexural strength tests by scanning electron microscope (AVE). 


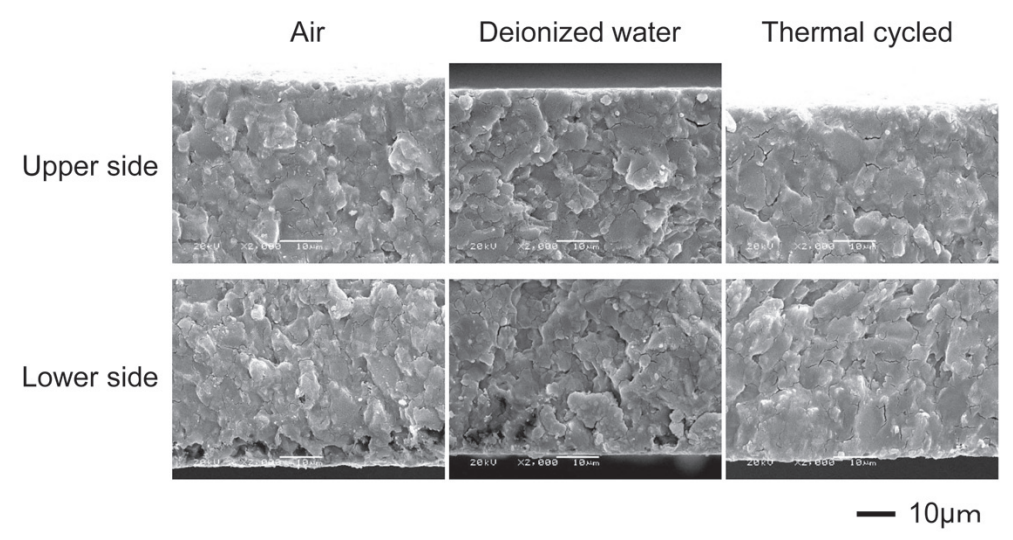

Fig. 9 Fractured surfaces of specimens after flexural strength tests by scanning electron microscope (ENA).

shows the fractured surfaces of CS300 specimens. The specimen stored in air revealed a surface fractured in a brittle manner and flat. In comparison with the specimen stored in air, the specimens stored in water and after thermal cycling showed rougher surfaces and cracks on the compressed side of the specimen.

Figure 7 shows the fractured surfaces of $\mathrm{HC}$ specimens after flexural strength tests. Spherical filler shapes were observed on the fractured surfaces. The specimens stored in air and in water for 7 days had rougher surfaces. The specimens after thermal cycling also showed a rougher surface and less filler was exposed than for the specimens stored in air or in water for 7 days.

Figure 8 shows the fractured surfaces of AVE specimens after flexural strength tests. Compared to other resin blocks, cracks were observed at the compressed side of specimens for all storage conditions. The specimens stored in air and in water for 7 days showed hackle-shape or mirror-like cracks on the tension stress side, as often seen in brittle fractures ${ }^{24)}$.

Figure 9 shows the fractured surfaces of ENA specimens after flexural strength tests. The specimens stored in air and in water for 7 days both exhibited a rough surface with sharp edges. The fractured surface of the specimen after thermal cycling had a smoother appearance compared to those stored in air and in water for 7 days.

\section{DISCUSSION}

The present study determined the flexural strengths of resin composite materials. The results indicated that CS300 had the greatest strength and HC had the least strength under all experimental conditions $(p<0.05)$. Regarding the flexural moduli, ENA showed the highest values and $\mathrm{HC}$ the lowest values under all experimental conditions $(p<0.05)$. Except for CS300 and ENA, the resin blocks examined revealed lower flexural strengths after 7-day water immersion or 10,000 thermal cycles than after storage in air at room temperature $(p<0.05)$.
In this study, the specimens were subjected to thermal cycling between $5^{\circ} \mathrm{C}$ and $55^{\circ} \mathrm{C}$ in deionized water for 10,000 cycles. Each cycle was $60 \mathrm{~s}$ at each temperature with $30 \mathrm{~s}$ of dwell time in air at $23 \pm 2^{\circ} \mathrm{C}$ between temperature conditions. These experimental conditions were selected based on previous studies ${ }^{25-29}$. The 10,000 cycles in this study were considered to be equivalent to approximately 2 years and 6 months in the oral cavity, assuming 10 thermal cycles in the oral cavity per day ${ }^{30}$.

The flexural strengths of resin blocks stored in air at room temperature ranged from 133 to $270 \mathrm{MPa}$. Conventional dental composite resins and hybrid resins for crown and bridge are reported to have flexural strengths ranging from 169.1 to $196.0 \mathrm{MPa}^{4)}$. Some of the resin blocks we examined showed greater flexural strength than the conventional dental composite resins for crown and bridge (resin jacket crown). The flexural moduli of the resin blocks in this study ranged from 9.0 to $29.3 \mathrm{GPa}$, whereas those of the conventional dental composite resins for crown and bridge (resin jacket crown) are reported to range from 9.4 to $21.4 \mathrm{GPa}^{4)}$. This suggests that the strength and elastic moduli of the resin blocks examined in this study are acceptable for clinical application.

The present study showed no significant differences in flexural strength between the resin blocks stored in water for 7 days or thermocycled for 10,000 cycles and those stored in air $(p>0.05)$.

Ferracane $^{31)}$ reported that polymers used in dental restorative materials are subject to both hygroscopic and hydrolytic effects that may influence their mechanical properties, dimensional stability and biocompatibility.

The water absorptions of resin composite were previously reported by many researchers ${ }^{32-36)}$. Fan et $a l^{32)}$ reported that the water sorption in direct restorative resins occurs in the organic resin matrixes. Thus, a more valid expression of water sorption values is the amount of water absorbed per unit weight of organic matrix content (resin matrix). It is more indicative of the water sorption characteristics of the resin matrix. Sideridou et 
$a l .{ }^{33)}$ reported that the water sorption at equilibrium for poly (Bis-EMA), poly (Bis-GMA), poly (UDMA) and poly (TEGDMA) were 1.8, 2.6, 2.9 and $6.3 \mathrm{wt} \%$, respectively. Polymers made with the UDMA monomer exhibit similar or slightly less water sorption than those prepared from Bis-GMA, however, UDMA polymers show significantly more water uptake than polymers based on nonhydroxylated Bis-GMA analogues such as Bis-EMA.

Musanje and Darvell ${ }^{34)}$ reported that water sorption not only affects physical and mechanical properties, especially of composite resins but also decreases surface hardness and elastic modulus. Ito et al. ${ }^{35)}$ reported that the least hydrophilic resin (E-Bis-GMA and TEGDMA) absorbed 0.55 wt $\%$ water and showed a $15 \%$ decrease in modulus after 3 days and the most hydrophilic experimental resin (Bis-GMA and HEMA) absorbed 12.8 wt $\%$ water and showed a $73 \%$ modulus decrease during the same periods.

Therefore, the resin block used this study is considered to have low water absorption of the resin block because the main monomers are UDMA and BisMEPP. Under the present experimental conditions, water sorption was considered not to noticeably influence the flexural strength of the resin blocks examined.

As for the main resin monomers used in the materials, HC and AVE are composed of UDMA, and ENA is composed of UDMA and TEGDMA. Both CS300 and CS270 employ Bis-MEPP and UDMA. All the resin composites in this study were made from similar resin matrix monomers, but CS300 and CS270 used Bis-MEPP in addition to UDMA. This difference in resin monomer composition from other materials possibly increased the flexural strength of these two materials. The composites based on dimethacrylates without hydroxy groups (BisMEPP) showed a relatively greater flexural strength than those with hydroxy groups (Bis-GMA) under wet conditions $^{37}$. Bis-MEPP is also known to be a rigid monomer $^{38)}$.

The stable and greater flexural strength of CS300 in this study could be explained by the use of Bis-MEPP, having lower water sorption, as a matrix component and filler content in the resin composite block. Furthermore, the production process for CS300 may be different from other resin blocks, increasing the degree of polymerization and density.

Although CS270 contained a similar matrix resin and filler to CS300, CS270 showed lower flexural strength. This difference in strength may have stemmed from a difference in filler content in the resin composite block.

Water sorption of matrix components and reduction of bonding force between resin matrix and filler are known to affect the deterioration of resin composite materials ${ }^{16-19)}$. The resin components of CS300 and CS270 blocks are mainly composed of Bis-MEPP, which shows hydrophobic behavior, and UDMA, which is still hydrophobic but rather hydrophilic compared to Bis$\mathrm{MEPP}^{37}$. Although water likely penetrated into the resin blocks by immersion in water, the matrix resin components would absorb less water because of their hydrophobic nature. Therefore, the water may have had a greater effect reducing the bonding of resin matrix and filler in CS300 and CS270 resin blocks.

Filler content determinations in resin composites should be measured by volume ratio. In recent years, fillers incorporated in resin composites were included both organic composite fillers and inorganic fillers. In the previous report ${ }^{5,8}$, the mass of the specimen after heating, as the mass of inorganic fillers in the composite material, was divided by the initial mass of the specimen to obtain the amount of inorganic filler as a simple method for measuring the filler content. Therefore, we calculated the inorganic filler content based on the mass fraction and considered that it could be effective in examining the relationship between the strength and filler content of the resin composites.

From the results of filler content determinations, the inorganic filler content ranged from 57.4 to $85.2 \mathrm{mass} \%$, and ENA had the largest filler content among the materials examined in this study. It is generally believed that an increase in filler content increases the strength and the hardness of resin composite materials ${ }^{39-42)}$. ENA showed the greatest Vickers hardness value, while that of $\mathrm{HC}$ was the lowest $(p<0.05)$. We found a significant positive correlation between Vickers hardness and filler content $(p<0.05, \mathrm{r}=0.850)$, and a trend that an increase in filler content increased the Vickers hardness. However, there was no significant correlation between flexural strength and filler content in this study $(p>0.05$, Fig. 4). Regarding the flexural moduli of materials, ENA showed the greatest value and $\mathrm{HC}$ the lowest, as seen in the Vickers hardness experiments $(p<0.05)$. A significant positive correlation was found between flexural modulus and filler content $(p<0.05, \mathrm{r}=0.877)$. The results suggested that the flexural moduli were influenced by the filler contents and the filler compositions; ENA, which had the greatest filler content and contained feldspar glass with a large amount of $\mathrm{Al}_{2} \mathrm{O}_{3}$, revealed a greater flexural modulus value than the other resin composites containing quartz as filler. Masouras et $a l .{ }^{43)}$ found that the elastic moduli of some resin composite materials were positively correlated to their filler contents. Randolph et $a l^{44)}$ and Mainjot et al. ${ }^{45)}$ reported that modern resin composites with high inorganic filler content were associated with higher flexural modulus and strength. The results of the present study supported these previous reports.

The flexural strengths did not correlate to the filler content, and are considered to be affected more by the composition of the resin matrix than by the filler content and composition.

Resin composite materials were reported to deteriorate due to residual stress yield ${ }^{30}$. Since the polymerization of resin matrix components continues after setting, both polymerization shrinkage and shrinkage by cooling water the during thermal cycle process can cause residual stress in the resin matrix. In addition, because of the large difference in thermal expansion coefficient between the filler and the resin matrix, further complex residual stress is generated at the resin matrix/filler interface. These residual stresses 
are considered to induce the deterioration of materials that fracture in a brittle manner.

Ferracane et $a .^{46)}$ reported that water penetration into the matrix generates softening of the polymerized matrix when immersing resin composites in water. Druck et $a l .{ }^{47)}$ reported that water immersion led to hydrolysis of silane coupling agents at the interface between filler and matrix, and that hydrolysis notably occurred in resin composites using zirconia fillers. In $\mathrm{HC}, \mathrm{KZR}$ and EST, which use zirconium silicate, $\mathrm{SiO}_{2}-\mathrm{Al}_{2} \mathrm{O}_{3}-\mathrm{ZrO}_{2}$, and zirconia, respectively, as fillers, the silane coupling agents at the matrix/filler interface could be hydrolyzed by water immersion, resulting in a decrease in flexural strength by reducing the bonding force between filler and matrix. AVE, which does not use zirconia as a filler component, employs UDMA as a matrix component. Since UDMA is rather hydrophilic compared to BisMEPP, as mentioned above, the flexural strength of AVE was possibly lower due to enhanced hydrolysis of the silane coupling agent at the matrix/filler interface by water penetration through the matrix.

In fracture surface observations, all of the resin blocks revealed somewhat rough surfaces fractured in a brittle manner. It could be speculated from this finding that the resin blocks examined absorbed less water in the matrix. The result that, except for CS300 and ENA, the resin blocks showed decreased flexural strength after 10,000 thermal cycles compared to storage in air at room temperature, would be due to an effect of hydrolysis of the coupling agents at the matrix/filler interface rather than direct water absorption in the matrix resin.

Under the present experimental conditions, the resin composite block CS300 exhibited the greatest flexural strength among all storage conditions and less deterioration of strength by thermal cycling and water immersion among the resin composite blocks examined. None of the CAD/CAM resin blocks showed significant differences in flexural strength between storage in water and thermal cycling $(p>0.05)$. Therefore, the experimental results rejected the proposed hypothesis.

\section{CONCLUSIONS}

Under the present experimental conditions, the following conclusions were drawn:

1. The flexural strengths differed among the resin composite materials for $\mathrm{CAD} / \mathrm{CAM}$ due to differences in matrix and/or filler compositions.

2. The difference in storage condition between water immersion and thermal cycling did not affect the flexural strengths of resin composite materials for CAD/CAM examined in this study.

3. The resin composite block CS300 showed the greatest flexural strength for all storage conditions and less deterioration of strength by thermal cycling and water immersion among the resin composite blocks.

\section{CONFLICT OF INTEREST}

No conflict of interest exists for any of the authors of this paper. This research received no specific grant from any funding agency in the public, commercial or not-forprofit sectors.

\section{REFERENCES}

1) Miyazaki T, Hotta Y, Kuriyama S, Tamaki Y. A review of dental CAD/CAM: current status and future perspectives from 20 years of experience. Dent Mater J 2009; 28: 44-56.

2) van Noort R. The future of dental devices is digital. Dent Mater 2012; 28: 3-12.

3) Miyazaki T, Hotta Y. CAD/CAM systems available for the fabrication of crown and bridge restorations. Aust Dent J 2011; 56 (1 Suppl): 97-106.

4) Hamakubo Y, Sawase T, Yoshida K, Kamada K, Taira Y, Atsuta M. The physical properties of a machinable resin composite for esthetic restorations. Dent Mater J 2005; 24: 24-29.

5) Lauvahutanon $\mathrm{S}$, Takahashi $\mathrm{H}$, Shiozawa M, Iwasaki N, Asakawa Y, Oki M, et al. Mechanical properties of composite resin blocks for CAD/CAM. Dent Mater J 2014; 33: 705-710.

6) Lauvahutanon S, Takahashi H, Oki M, Arksornnukit M, Kanehira M, Finger WJ. In vitro evaluation of the wear resistance of composite resin blocks for CAD/CAM. Dent Mater J 2015; 34: 495-502.

7) Handa K, Murakami N, Yamazaki T, Takahashi H, Wakabayashi N. The ball-on-disk cyclic wear of CAD/CAM machinable dental composite and ceramic materials. J Oral Sci 2017; 59: 589-596.

8) Kameyama Y, Ohashi K, Yamaguchi H, Miyake K, Wada Y, Midono T, et al. Mechanical properties of hybrid resin blocks for CAD/CAM crown. J J Dent Mater 2017; 36: 453-459.

9) Koizumi H, Saiki O, Hiraba H, Okazaki T, Matsumura H. Surface roughness and gloss of current CAD/CAM resin composites before and after toothbrush abrasion. Dent Mater J 2015; 34: 881-887.

10) Kamonkhantikul K, Arksornnukit M, Lauvahutanon S, Takahashi H. Toothbrushing alters the surface roughness and gloss of composite resin CAD/CAM blocks. Dent Mater J 2016; 35: 225-232.

11) Bähr N, Keul C, Edelhoff D, Eichberger M, Roos M, Gernet $\mathrm{W}$, et al. Effect of different adhesives combined with two resin composite cements on shear bond strength to polymeric CAD/ CAM materials. Dent Mater J 2013; 32: 492-501.

12) Higashi M, Matsumoto M, Kawaguchi A, Miura J, Minamino $\mathrm{T}$, Kabetani $\mathrm{T}$, et al. Bonding effectiveness of self-adhesive and conventional-type adhesive resin cements to CAD/CAM resin blocks. Part 1: Effects of sandblasting and silanization. Dent Mater J 2016; 35: 21-28.

13) Kawaguchi A, Matsumoto M, Higashi M, Miura J, Minamino $\mathrm{T}$, Kabetani T, et al. Bonding effectiveness of self-adhesive and conventional-type adhesive resin cements to CAD/CAM resin blocks. Part 2: Effects of ultrasonic and acid cleaning. Dent Mater J 2016; 35: 29-36.

14) Cekic-Nagas I, Ergun G, Egilmez F, Vallittu PK, Lassila LVJ. Micro-shear bond strength of different resin cements to ceramic/glass-polymer CAD-CAM block materials. J Prosthodont Res 2016; 60: 265-273.

15) Yamaguchi H, Kameyama Y, Miyake K, Ohashi K, Wada $Y$, Midono T, et al. Adhesion durability of resin-based luting agents to resin composite blocks for $\mathrm{CAD} / \mathrm{CAM}$ crown. Adhes Dent 2016; 34: 133-140.

16) Schneider LFJ, Cavalcante LM, Siikas N, Watts DC. Degradation resistance of silorane, experimental ormocer and dimethacrylate resin-based dental composites. J Oral Sci 
2011; 53: 413-419.

17) Bagheri R, Tyas MJ, Burrow MF. Comparison of the effect of storage media on hardness and shear punch strength of tooth-colored restorative materials. Am J Dent 2007; 20: 329334.

18) Sarrett DC, Ray S. The effect of water on polymer matrix and composite wear. Dent Mater 1994; 10: 6-10.

19) Arikawa H, Kuwahata H, Seki H, Kanie T, Fujii K, Inoue K. Deterioration of mechanical properties of composite resins. Dent Mater J 1995; 14: 78-83.

20) Da Fonte Porto Carreiro A, Dos Santos Cruz CA. Hardness and compressive strength of indirect composite resins: effect of immersion in distilled water. J Oral Rehabil 2004; 31: 1085-1089.

21) Erdemir U, Yildiz E, Eren MM, Ozel S. Surface hardness of different restorative materials after long-term immersion in sports and energy deinks. Dent Mater J 2012; 31: 729-736.

22) ISO 6872; Dentistry-Ceramic materials. 2015.

23) JDMAS 245; Resin blocks for dental restoration using CAD/ CAM system. 2017.

24) Quinn GD. In: Special publication 960-16 Fractography of ceramics and glasses. National Institute of Standard and Technology; 2007. p.5-1-5-70.

25) Montes-G GM, Draughn RA. In vitro surface degradation of composites by water and thermal cycling. Dent Mater 1986; 2: 193-197.

26) Yao J, Li J, Wang Y. Comparison of the flexural strength and marginal accuracy of traditional and CAD/CAM interim materials before and after thermal cycling. J Prosthet Dent 2014; 112: 649-657.

27) Morresi AL, D'Amario M, Monaco A, Rengo C, Grassi FR, Capogreco M. Effects of critical thermal cycling on the flexural strength of resin composites. J Oral Sci 2015; 57: 137-143.

28) Kadiyala KK, Badisa MK, Anne G, Anche SC, Chiramana $\mathrm{S}$, Muvva SB, et al. Evaluation of flexural strength of thermocycled interim resin materials used in prosthetic rehabilitation -An in-vitro study. J Clin Diagn Res 2016; 10: 91-95.

29) Tsujimoto A, Barkmeier WW, Takamizawa T, Latta MA, Miyazaki M. Influence of thermal cycling on flexural properties and simulated wear of computer-aided design/ computer-aided manufacturing resin composites. Oper Dent 2017; 42: 101-110.

30) Miyazaki T, Suzuki E, Miyaji T. The influence of thermal cycling on the mechanical properties of posterior restorative composite resins. J Dent Mater 1986; 5: 187-195.

31) Ferracane JL. Hygroscopic and hydrolytic effects in dental polymer networks. Dent Mater 2006; 22: 211-222.

32) Fan PL, Edahl A, Leung RL, Stanford JW. Alternative interpretations of water sorption values of composites resins. J Dent Res 1985; 64: 78-80.

33) Sideridou I, Achikias DS, Spyroudi C, Karabela M. Water sorption, solubility and modulus of elasticity of light-cured dimethacrylate-based dental resins. Biomaterials 2003; 24: 655-665.

34) Musanje L, Darvell BW. Aspects of water sorption from air, water and artificial saliva in resin composite restorative materials. Dent Mater 2003; 19: 414-422.

35) Ito s, Hashimoto M, Wadgaonkar B, Svizero N, Carvalho RM, Yiu C, et al. Effects of resin hydrophilicity on water sorption and changes in modulus of elasticity. Biomaterials 2005; 26: 6449-6459.

36) Liebermann A, Wimmer T, Schmidlin PR, Scherer H, Löffler $\mathrm{P}$, Roos $\mathrm{M}$, et al. Physicomechanical characterization of polyetheretherketone and current esthetic dental CAD/CAM polymers after aging in different storage media. J Prosthet Dent 2016; 115: 321-328.

37) Kawaguchi M, Fukushima T, Horibe T. Effect of monomer structure on the mechanical properties of light-cured composite resin. Dent Mater J 1989; 8: 40-45.

38) Murata T, Kimura T, Ueno T, Kumagai T. Mechanical properties of novel injectable composite resin, G-ænial universal injectable. 96th general session of International Association of Dental Research, 2018, abstr.2000.

39) Kim KH, Ong JL, Okuno O. The effect of filler loading and morphology on the mechanical properties of contemporary composites. J Prosthet Dent 2002; 87: 642-649.

40) Adabo GL, dos Stantos Cruz CA, Fonseca RG, Geraldo Vaz L. The volumetric fraction of inorganic particles and the flexural strength of composites for posterior teeth. J Dent 2003; 31: 353-359.

41) Ikejima I, Nomoto R, McCabe JF. Shear punch strength and flexural strength of model composites with varying filler volume fraction, particle size and silanation. Dent Mater 2003; 19: 206-211.

42) Chung KH, Greener EH. Correlation between degree of conversion, filler concentration and mechanical properties of posterior composite resins. J Oral Rehabil 1990; 17: 487-494.

43) Masouras K, Silikas N, Watts DC. Correlation of filler content and elastic properties of resin-composites. Dent Mater 2008; 24: 932-939.

44) Randolph LD, Palin WM, Leloup G, Leprince JG. Filler characteristics of modern dental resin composites and their influence on physico-mechanical properties. Dent Mater 2016; 32: 1586-1599

45) Mainjot AK, Dupont NM, Oudkerk JC, Dewael TY, Sadoun MJ. From artisanal to CAD-CAM blocks: State of the art of indirect composites. J Dent Res 2016; 95: 487-495.

46) Ferracane JL, Berge HX, Condon JR. In vitro aging of dental composites in water - Effect of degree of conversion, filler volume, and filler/matrix coupling. J Biomed Mater Res 1998; 42: 465-472.

47) Druck CC, Pozzobon JL, Callegari GL, Dorneles LS, Valandro LF. Adhesion to Y-TZP ceramic: Study of silica nanofilm coating on the surface of Y-TZP. J Biomed Mater Res B 2015; 103: $143-150$ 